\title{
The shear bond strength of reconditioned sapphire bracket after rebonding with sandblasting zirconia
}

\author{
Dedeh Pitriani*, Setiadi W. Logamarta*, Dian N. Agus Imam* \\ *Department of Orthodontics Faculty of Dentistry Jenderal Soedirman University, Indonesia
}

\begin{abstract}
Introduction: Sapphire bracket is the best aesthetic bracket with metal bracket-like mechanical properties. In conditions causing attachment lost between sapphire bracket and enamel, a rebonding procedure will needed. The shear bond strength of sapphire bracket decrease after the rebonding procedure. Sandblasting, hydrofluoric acid etching, and silanization as surface treatment are widely used to improve the bracket bond strength. The purpose of this study was to evaluate the effect of zirconia as sandblasting material towards the shear bond strength of reconditioned sapphire bracket. Methods: This study was an experimental laboratory with as much as 27 samples of sapphire bracket divided into 3 groups. Group I was rebonded with sandblasting zirconia and silane, group II with hydrofluoric acid etching and silane, and group III with new bracket bonding. The attachment strength measurement indicator was the shear bond strength test and the SEM analysis. Results: The shear bond strength test showed the average value for each group were $12.97 \mathrm{MPa}, 9.26 \mathrm{MPa}$, and $10.58 \mathrm{MPa}$, consecutively. The test results were then analysed using a one way ANOVA and LSD $(p<0.05)$, which showed that significant difference only found in the comparison between group I with group II, but not in the comparison between group I with group III. The SEM analysis result showed that sandblasted surface has homogenous microporosities in high quantities. Conclusion: Zirconia as sandblasting material was effective in increasing the shear bond strength of reconditioned sapphire bracket.
\end{abstract}

Keywords: Sandblasting, sapphire bracket, shear bond strength, zirconia.

p-ISSN 1979-0201, e-ISSN 2549-6212 Available from: http://jurnal.unpad.ac.id/pjd/article/view/13602

DOI: http://dx.doi.org/10.24198/pjd.vol29no1.13602

Submission: Dec 2017 Publishing: Mar 2018

\section{INTRODUCTION}

The sapphire bracket is a type of ceramic bracket that has the best aesthetic value and mechanical properties equivalent to a metal bracket. Another advantage of the sapphire bracket is the colour stability, non-toxic, corrosion resistant, and biocompatible. ${ }^{1}$ Conditions such as overly heavy chewing loads, tooth brushing processes that are too hard or deliberately removed due to debonding procedures, cause attachment between brackets and emails are released, so a re-attachment procedure is required. ${ }^{2}$ Strong adhesive sliding sapphire bracket decreases when re-attached 
because the surface of the sapphire bracket base is distorted due to debonding procedure or cleaning of adhesive residue. The addition of retention is required for the shear strength of shear to increase, for example sandblasting. ${ }^{3}$

Sandblasting is performed by firing abrasive material at a certain distance and pressure, which will clean up the remaining adhesive material and produce a new microporosity as mechanical retention. ${ }^{4}$ Materials commonly used as materials sandblasting in dentistry is aluminium oxide. Aluminium oxide is a ceramic material that has a high hardness but has brittle properties that easily break. These particles are shown to increase surface roughness and mechanical bonding.

Technological developments in natural resource processing, encouraging innovation by utilising local resources as raw materials. One of Indonesia's potential resources is zirconia. Zirconia is a mineral that is widely available in Indonesia, especially in Bangka and Kalimantan. ${ }^{6}$ Zirconia has a density of $6.42 \mathrm{~g} / \mathrm{cm} 3$, high strength, high fracture resistance, high hardness, and resistant to acid and base corrosion. In addition to these properties, zirconia has excellent biocompatibility and is quite aesthetic. ${ }^{7}$

Zirconia is widely used in the field of dentistry such as the manufacture of denture. ${ }^{8}$ Zirconia can be used as an abrasive material because it can maintain its particle shape. Zirconia can be used as an additional material to improve the mechanical properties of the material. ${ }^{7}$ One of them is a zirconate coupling agent that helps the non-silica ceramic adhesion. ${ }^{9}$

Background above, encouraging researchers to see the effect of the use of zirconia as a sandblasting material against the shear bonding strength of reconditioning the base of the sapphire bracket. A scanning electron microscopy (SEM) test was used to assess surface morphology after sandblasting, and a shear bond strength test was used to measure the effectiveness of the bracket attachment. $^{1}$

\section{METHODS}

The type of research conducted was a pure laboratory experimental research with post test only control group design. The research was conducted at the Basic Dentistry Laboratory of
Jenderal Soedirman University. The number of samples in this study was 27 samples divided into three treatment groups. The materials used in this study were American Orthodontics ${ }^{\circledR}$ Radiance Plus sneak bracket, mandibular first premolar teeth, light cure adhesive bonding, zirconia, cold acrylic resin, 9\% hydrofluoric acid, 37\% phosphoric acid, and silane.

The research procedures were as follows: 1) Sample preparation: Acrylic prints are $13 \mathrm{~mm}$ in diameter and $7 \mathrm{~mm}$ in height. The maxillary premolar teeth were cut to $1 \mathrm{~mm}$ below the cementoenamel junction with the diamond of the bur disk and the cervical section covered in the night. The teeth were grown on acrylic with the buccal surface facing upwards. The sample picture can be seen in Figure 1 below.

The enamel particles were cleaned with pumice and water then etched with $37 \%$ phosphoric acid for 30 seconds, rinsed with running water for 10 seconds and dry. Afterwards, the bonding material was applied, the bracket was sticked to the buccal portion of the tooth with the bracket slot to the $4 \mathrm{~mm}$ cups. The bracket then pressed with $4 \mathrm{oz}$ force gauge or $113.4 \mathrm{~g}$ for 10 seconds. Irradiation was performed for 40 seconds with intensity $1000 \mathrm{~mW} / \mathrm{cm} 2$, incubated in an artificial saliva solution, temperature $37^{\circ} \mathrm{C}$ for 24 hours.

The bonding treatment was performed by fully polymerised the bonding material, then the

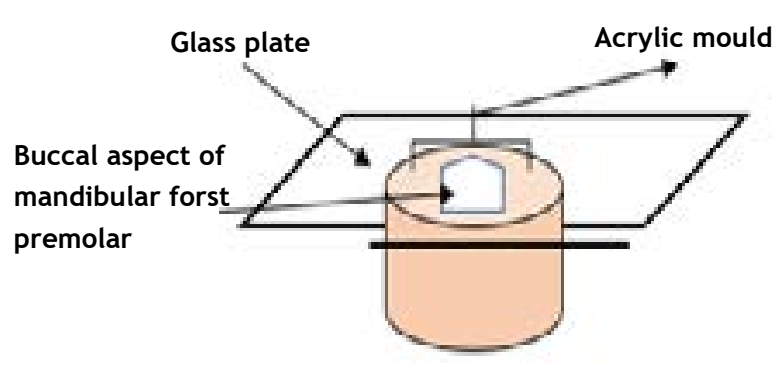

Figure 1. Sample mould

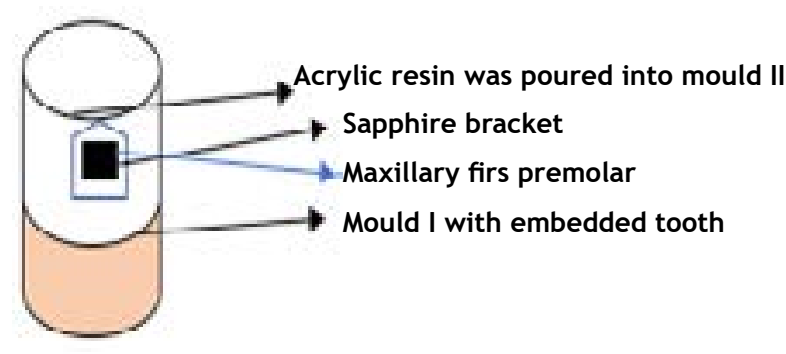

Figure 2. Sample mould II 
bracket was debonded to the tooth surface using a debonding plier. The technique used was the squeeze, both ends of pliers pressed on mesial and distal wings. Treatment in group I was performed by cleaning the remaining adhesive material with tungsten carbide round bur for 32 seconds, then the sandblasting procedure of $25 \mu \mathrm{m}$ zirconia for 30 seconds with a pressure of 2.3 bar and 900 angles. Treatment in group II was performed by cleaning the remaining adhesive material with tungsten carbide round bur for 32 seconds, then etched with $9 \%$ hydrofluoric acid for 20 seconds and rinsed with water. Treatment in Group III, no debonding procedure and re-attachment was performed. Scanning electron microscopy (SEM) test was performed after the surface treatment process, one sample from each group was not being rebonded. The sample was analysed by SEM to see the surface microporosity and to know the residual zirconia on the surface of the sapphire bracket.

The rebonding procedure was performed by cleaning the rest of the adhesive material on the buccal surface of the tooth with green stone bur low speed or scaler and pumice and water. The base of the bracket base was added with silane using a micro brush and repeated the bonding procedure. The sample on an uncoupled mould I was coated with vaseline. The second mould was placed over the sample, and the acrylic resin was manipulated and then loaded into the mould II. The description of the mould II can be seen in Figure 2 below.

Shear bond strength testing was performed towards reinstalled brackets using the universal testing machine. The results obtained in the form of load or shear force (F) in units of Newton (N). The data, included in the shear strength formula $\tau=F / A$ with $\tau=$ shear strength $(\mathrm{MPa}), \mathrm{F}=$ shear force $(\mathrm{N})$, and $\mathrm{A}=$ bracket base area $(\mathrm{mm2})$.

Data analysis was performed to see the normality of data using Shapiro Wilk test and see the homogeneity of data with the Shapiro-Wilk test. Furthermore, the parametric statistical test was performed in the form of one way ANOVA. One way ANOVA tested the hypothesis with one dependent variable. Then, followed by Post Hoc Least Significant Difference (LSD) analysis with 95\% confidence level $(\alpha=0.05)$ to see a significant difference between sample groups.

\section{RESULTS}

Test results of the shear bond strength using the universal testing machine tool was performed to see the shear bond strength of each group. The average value of the shear bond strength value can be seen in Table 1.

Figure 3 showed group I having the highest mean and group II having the lowest mean value. The data were tested for normality using Shapirowilk test with a p-value higher than 0.05 , showing normal distribution data. Normality test results can be seen in Table 2 .

Table 2 showed that the normality test values use the Shapiro-wilk test. This test showed that the $p$-value of the whole group was higher than 0.05 , so the data was normally distributed. Data was tested the homogeneity using Levene test with $\mathrm{p}$-value more than 0,05 indicating the data homogeneous. Homogeneity test results can be seen in Table 3.

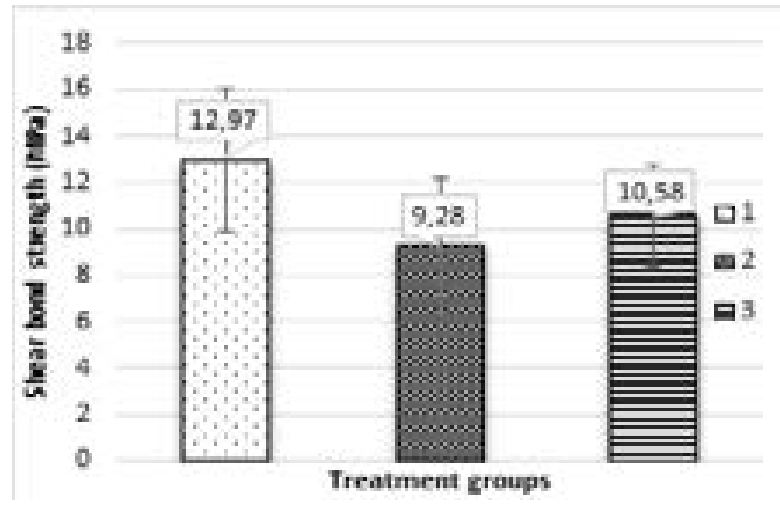

Figure 3. Graph of the mean and standard deviation of sapphire bracket shear bond strength

Table 1. The mean and standard deviation of sapphire brackte shear bond strength

\begin{tabular}{cccc}
\hline & $\begin{array}{c}\text { Group I } \\
\text { Sandblasting zirconia (MPa) }\end{array}$ & $\begin{array}{c}\text { Group II } \\
\text { Etsa 9\% Hydrofluoric acid etch (MPa) }\end{array}$ & $\begin{array}{c}\text { Group III } \\
\text { New Bonding (MPa) }\end{array}$ \\
\hline Mean & 12.97 & 9.26 & 10.58 \\
SD & 3.12 & 2.92 & 2.20 \\
\hline
\end{tabular}


Table 2. Shapiro-wilk normality data test of sapphire bracket shear bond strength

\begin{tabular}{ccccc}
\hline & \multirow{2}{*}{$\begin{array}{c}\text { Sample } \\
\text { group }\end{array}$} & \multicolumn{3}{c}{ Shapiro-wilk } \\
\cline { 3 - 5 } & Statistic & Sample number & $\mathrm{p}$ \\
\hline \multirow{2}{*}{ Shear } & I & 0.965 & 8 & 0.853 \\
bond & II & 0.910 & 8 & 0.351 \\
strength & III & 0.914 & 8 & 0.386 \\
\hline
\end{tabular}

Table 3. Levene homogeinity test result of sapphire bracket shear bond strength

\begin{tabular}{cccc}
\hline Levene statistic & df1 & df2 & p \\
\hline 0.968 & 2 & 21 & 0.396 \\
\hline
\end{tabular}

Table 4. One-way ANOVA statistic test result of the mean value of sapphire bracket shear bond strength

\begin{tabular}{ccccc}
\hline Groups & df & Variances & $\mathrm{f}$ & $\mathrm{p}$ \\
\hline Between groups & 2 & 28.36 & \multirow{2}{*}{3.66} & 0.043 \\
Inside group & 21 & 7.73 & & \\
\hline
\end{tabular}

Table 5. LSD statistic test result of the mean value of sapphire bracket shear bond strength

\begin{tabular}{cccc}
\hline & Group I & Group II & Group III \\
\hline Group I & & $0.014^{*}$ & 0.099 \\
Group II & $0.014^{*}$ & & 0.355 \\
Group III & 0.099 & 0.355 & \\
& &
\end{tabular}

Table 3 showed the homogeneity test values using Levene test. This test showed that the $\mathrm{p}$-value of the whole group was higher than 0.05 , so the data was homogeneous. Furthermore, one way ANOVA test was performed to determine the differences between groups. The test results can be seen in Table 4 .

From the test results can be concluded that there was a significant difference of the mean value of the shear bond strength between all research groups. The post-hoc least significant difference (LSD) test was performed to determine the significance of the differences in each group. The data was considered of having significant differences if the value of $p<0.05$. LSD test results can be seen in Table 5 .

Group I and group II had significant differences with the p-value of 0.014 . Group I and group III did not have significant differences, with the p-value of 0.099 , and group III with group II did not show any significant difference with the $\mathrm{p}$-value of 0.355 . After $9 \%$ hydrofluoric acid application and sandblasting procedure, one sample in each group was analysed by scanning electron microscopy (SEM) to see the microporosity formed, the remaining adhesive material on the bracket base, knowing the presence of sandblasting particles left on the surface of the
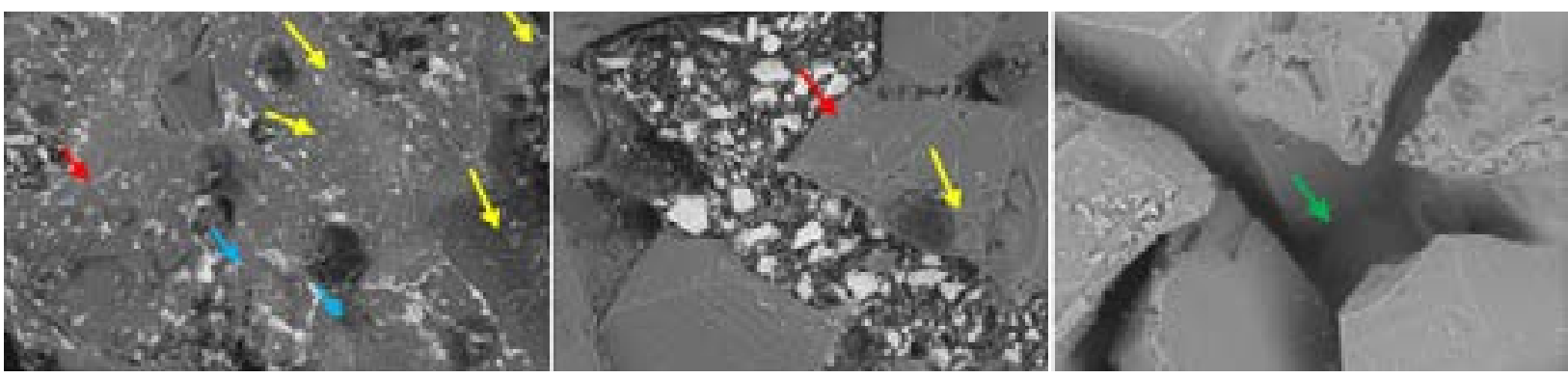

Figure 4. Description of the SEM results of $1000 \times$ magnification. (A) Group I; (B) Group II; (c) Group III.

The showed microporosity; the $\downarrow$ showed adhesive material residue; the $\downarrow$ showed zirconia particles residue; the $\downarrow$ showed new retention formation on the new bracket

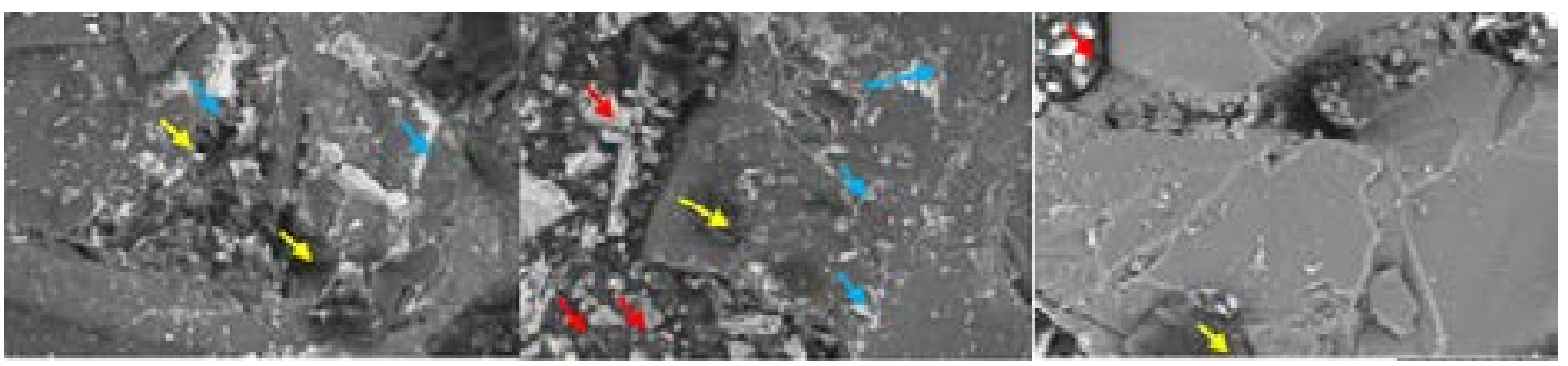

Figure 5. Description of the SEM results of 2000 x magnification. (A) Group I; (B) Group II; (c) Group III 
bracket base. SEM description of groups 1 and group 2 with magnification 1000x and 2000x can be seen in Figure 4 and Figure 5.

Microporosity was observed more in Group $\mathrm{I}$, and the size tends to be more similar. Around the microporosity was observed white particles with various sizes which were the zirconia sandblasting residue. Group II was seen as having less microporosity, and the size tends to be less homogenous than group I. Group III showed undercut retention.

\section{DISCUSSION}

Analysis of the shear bond strength of reconditioned sapphire bracket was presented in Table 1 . The reattachment with sandblasting zirconia plus silane treatment has the highest shear bond strength. One reason was that the zirconia particles being fired were able to heat the bracket base surface, resulting in the formation of a new microporosity that acted as micromechanical retention, as well as removing the remaining adhesive material on the undercut.

Figure 2 showed the microporosity generated by a large number of zirconia sandblasting procedures with uniformly inclined sizes. A large number of microporosities of uniform size automatically create a more formed micromechanical interlocking and tend to have similar strength across the surface, resulting in stronger attachment, and increased shear strength increasing. The remaining adhesive material in group I was less than group II. Sandblasting zirconia effectively removes the remaining adhesive material on a bracket base. Optimal cleansing makes micromechanical interlocking between the adhesive material and the undercut stronger, thereby increasing the strength of retractable shear. The ability to clean up the rest of the adhesive material and form a new microporosity is what makes the micromechanical interlocking in group I to be increased. The results of this study were in accordance with previous research which stated that the sandblasting procedure was effective to clean the surface of the bracket base and increase the strength of ceramic bracket attachment. ${ }^{10}$

The area around the microporosity was a white particle of various sizes which is zirconia attached to the base of the bracket base and can be an instrument to enhance attachment. Zirconia particles have a large adsorption capacity against phosphate groups silane, the phosphoric methacrylate. Zirconia combined with phosphate groups will have an active surface and a high chemical affinity, thereby increasing attachment strength. Prior research suggests that increased attachment strength was obtained by bonding between phosphate monomers in lutting materials and zirconia surfaces. ${ }^{11}$

In addition to reacting with zirconia particles, the functional group on the silane would bind to the organic material on the adhesive material, and the inorganic material in the silane was able to bind with the sapphire bracket to form a siloxane (Si-O-Si) bond. The bond would increase the resin cement attachment by bracketing chemically, thereby increasing the shear strength of shear in group I. This result was in accordance with previous research stated that silane in bracket re-attachment procedure could provide adequate shear strength. ${ }^{2}$

Table 2 showed the second group of reactortreated groups with $9 \%$ hydrofluoric acid etching application plus silane having the lowest average shear bond strength. This condition may occur because the microporosity was formed less with more varied size. Consequently, micromechanical interlocking is formed less with less stable power, so the shear bond strength of attachment tends to be less than the maximum, and this makes the average strong shear adhesive in group II to the lowest.

The etching may dissolve the debris on the surface of the bracket base, in Figure 5 of the base surface of the bracket after cleaner etching. This condition will increase the surface energy so that it can optimise the bond between the silane with adhesive and bracket. The bond formed is a siloxane bond ( $\mathrm{Si}-\mathrm{O}-\mathrm{Si}$ ), which was the functional group on the silane binds with the adhesive material, and the inorganic group binds to the bracket. Thus, despite the low shear bond strength of group II, it still achieved a clinically acceptable standard of 6-8 $\mathrm{MPa}$.

The LSD test in Table 4 showed significant differences between group I and group II. This result was influenced by the pattern of microporosity formed in group 1 more and tend 
to be uniform, the remaining adhesive material of group I is less than group II, and the remaining part of zirconia particles left in group I so that the average of shear bond strength was higher than Group II.

Table 1 showed that group III of the new rebonded bracket had a higher mean value than Group II but lower than Group I. The attachment to the new bracket was obtained by the mechanical bond between the bracket and the adhesive material. The surface of the bracket base in Group III has mechanical retention of the undercut, resulting in an adequate micromechanical interlocking between the bracket and the adhesive material. The result obtained was the optimal shear strength of the bracket attachment.

The LSD test between group III and group I showed no significant difference. This condition showed that the procedure of re-attachment with sandblasting zirconia method was able to produce the shear that is not much different from new attachment. Sandblasting with zirconia can clean the residual adhesive material on the surface of the bracket base while forming a microporosity that serves as mechanical retention.

Bonding between silanes with sandblasting particles and adhesive materials are able to help improve attachment strength. Therefore, the shear bond strength of produced by group I was equivalent to a new attachment bracket. The results of previous studies stated that the rebonded ceramic bracket by the sandblasting procedure had a shear bond strength comparable to the new attachment. ${ }^{12}$ The rebonded procedure with sandblasting plus silane yields high shear strength and the equivalent of a new bracket attachment strength. ${ }^{2}$

The SEM image showed the surface of the rebounded sapphire bracket base after the sandblasting procedure using zirconia to have more microporosity and a uniformly inclined shape. This result was caused due to the microporosity formation mechanically through zirconia particles that were fired at a certain pressure and duration, thus causing friction between the sandblasting particles with the bracket base. Friction between particles causes the surface to become hot and melt, resulting in the formation of microporosity. More sandblasting microporosity patterns of this uniform size tend to cause micromechanical interlocking to increase. Microporosity pattern in group II was formed from chemical activity, namely hydrofluoric acid which dissolved the structure in the ceramic to form microporosity and looks like there was an open structure. The interaction between hydrofluoric acid and silica partly forms insoluble hexafluorosilicate, and the other half dissolves the silica. As a result, the crystalline structure is open, and microporosity is formed. Such conditions can increase the surface energy, and the addition of silanes will increase the effectiveness of attachment. The resulting microporosity was less, the effectiveness of attachment decreases, hence the lowest shear strength compared to the other groups.

\section{CONCLUSION}

Zirconia as sandblasting material was effective in increasing the shear bond strength of reconditioned sapphire bracket.

\section{REFERENCES}

1. Brantley WA, Eliades T. Orthodontic materialscientific and clinical Aspects. New York: Thieme Stuttgart. 2001.

2. Falkensammer $F$, Jonke $E$, Bertl $M$, Freudentahler J, Bentleon HP. Rebonding performance of different ceramic brackets conditioned with a new silane coupling agent. Eur J Orthod 2013;35:103-9.

3. Jena K, Duggal R, Mehrotra AK. Physical properties and clinical characteristics of ceramic bracket: A comprehensive review. Trends Biomater 2007;20(2):138-41.

4. Chetan GB, Muralidhar RY. Comparative evaluation of four office reconditioning methods for orthodontic stainless steel bracket on shear bond strenth: An In Vitro Study. Essences Dentistry 2011;3:6-13.

5. Andrade PHR, Reges RV, Lenza MA. Evaluation of shear bond strength of different treatments of ceramic bracket surfaces. Dental Press J Orthod 2012;17(4):17el-8. DOI:10.22159/ ijap.2017.v9s2.16

6. Sudjoko D, Triyono. Peningkatan kualitas zirkonia hasil olahan pasir zirkon. Ganendra 2008;XI(1):11-16. 
7. Christache $C M$, Burlibasa $M$, Cristache $G$, Drafta S, Popovici A, Iliescu AA, et al. Zirconia and its biomedical application. Metalurgia International 2011;16(7):18-23.

8. Saridag $\mathrm{S}$, Tak $\mathrm{O}$, Alniacik $\mathrm{G}$. Basic properties and type of zirconia : An overview. World J Stomatol. 2013;2(3):40-47.

9. Thompson JY, Stoner BR, Piascik JR, Smith R. Adhesion/cementation to zirconia and other non-silicate ceramics: What are we now? Dent Mater 2011;27(1):71-82. DOI:10.1016/j. dental.2010.10.022.

10. Guarita MK, Moresca AH, Losso EM, Moro A, Moresca RC, Correr GM. Effect of different surface treatment for ceramics bracket base on bond strength of rebonded brackets. Braz Dent J 2015;26(1):61-5. DOI:10.1590/01036440201300234.

11. Nishigawa G, Maruo $\mathrm{Y}$, Irie $M$, Maeda $N$, Yoshihara K, Nagaoka $\mathrm{N}$, et al. Various effect of sandblasting of dental restorative materials. Plos One Journal. 2016;11(1):1-10. DOI:10.1371/0147077.

12. Al Maaitah EF, Alomari S, Alhaija SAA, Safi AA. The effect of different bracet base cleaning method on shear bond strength of rebonded bracketr. J Contemp Dent Pract 2013;14(5):866-70. 